\section{Confidence intervals for nonlinear regression: A BASIC program}

\section{STEPHEN JOSÉ HANSON \\ Arizona State University, Tempe, Arizona 85281}

In psychological experiments linearity is desirable and usually realized. Some models, however, cannot avoid the nonlinearity of the underlying processes, or, for descriptive models, the obvious coordinate systems ( $\log -\log$, semilog, probit, etc.) which leave the data nonlinear have been tried and failed. In any case, nonlinear regression becomes appropriate.

Recent examples of parameters that appear in intrinsically nonlinear equations are arousal constants (Killeen, 1975), expectancy thresholds (Gibbon, 1977), transfer parameters (Davis \& Levine, 1977), intellectual growth parameters (Zajonc \& Markos, 1975), generalization factors (Blough, 1975), coupling constants (Staddon, 1977), cost parameters (Staddon, in press), consolidation parameters (Wickelgren, 1976), salience parameters (Rescorla \& Wagner, 1972), and search constants (Norman \& Rumelhart, 1970). Unless a large amount of data variance is accounted for or confidence intervals are established, the relationships or critical differences between parameters cannot be assessed.

This paper briefly outlines a method to obtain confidence intervals from nonlinear regression and demonstrates the use of a BASIC program employing this algorithm for computing confidence intervals for any nonlinear function regardless of the regression method.

Confidence Intervals for Nonlinear Regression. Suppose observations from an experiment arise as $\left(\mathrm{y}_{1}, \mathrm{t}_{1}\right),\left(\mathrm{y}_{2}, \mathrm{t}_{2}\right) \ldots\left(\mathrm{y}_{\mathrm{n}}, \mathrm{t}_{\mathrm{n}}\right)$. The standard regression model is of the form

$$
y_{i}=F\left(t_{i}, \theta\right)+\epsilon_{i},
$$

where, as usual, the $\epsilon_{\mathrm{i}}$ are assumed to be normally distributed with mean zero and common variance.

If $F(\theta)$ is an $n$ by $p$ matrix with elements

$$
=\left[\delta \mathrm{F}\left(\mathrm{t}_{\mathrm{i}}, \theta_{\mathrm{i}}\right)\right] / \delta \theta_{\mathbf{i}},
$$

then the matrix $\left(\mathrm{F}^{\prime} \mathrm{F}\right)_{\mathrm{pxp}}^{-1}$ contains in the diagonals the variances of the $p$ parameters. Denote this inverse matrix as $\hat{C}$; then the $95 \%$ confidence interval may be found for the ith parameter given the .025 critical value of a $t$ variate with $n-p$ degrees of freedom as

$$
\theta_{\mathrm{i}} \pm \mathrm{t}_{.025} \sqrt{\hat{\mathrm{c}}_{\mathrm{ii}}} \mathrm{s} \text {. }
$$

Similarly, a $t$ value for each parameter may be constructed by computing the ratio

$$
\theta_{\mathrm{i}} / \sqrt{\hat{\mathrm{c}}_{\mathrm{ii}}} \mathbf{s},
$$

where $s$ is the $\sqrt{1 /(\mathrm{n}-\mathrm{p}) \Sigma\left(\mathrm{y}_{\mathrm{j}}-\mathrm{F}\left(\mathrm{t}_{\mathrm{i}}, \theta_{\mathrm{i}}\right)\right)^{2}}$ and $\hat{\mathrm{C}}_{\mathrm{ii}}$ is the ith diagonal element from $\hat{c}$ (cf. Gallant, 1975; also see for convergence properties of these statistics).

Program Parameters. The following input information is either specified in the initial queries or documented in various points in the program CONF. Initially, the user-defined function FNA should be input at line 1 of the program (see Figure 1). All computations later will be made on FNA. Any nonlinear function may be input into the program this way as long as the variable is $\mathrm{T}$ and the parameters are written as $\mathrm{P}(1), \mathrm{P}(2), \ldots \mathrm{P}(\mathrm{i})$. These parameter positions in the function should be noted as they must be input into the same positions as they appear in this function.

The program asks first for the number of parameters and the number of data points. Next, it needs the sum of the squares residual (s); if only error variance is output, $\mathrm{s}$ may be computed by

$$
s=\sqrt{\text { error variance } n /(n-p) .}
$$

Finally, input each estimated value of the parameter from the regression into the $P$ vector. The program asks for each parameter in the equation sequentially to be input into $P(i), i=1,2, \ldots p$ (see Figure 2).

The program begins by numerically computing the partials of the user-defined function and filling the $F$ matrix, with these partials evaluated at the estimated values of the parameters and observation points $t_{i}$. Next, an inversion is performed on the $F^{\prime} F$ matrix through a Gauss-Jordan reduction. The diagonal elements of this matrix are the variances of the parameters. Thus, the standard error (SE), a $t$ value, and confidence intervals for the parameters may all be defined.

The statistical properties of the parameters are useful in that they can be given some interpretation. For example, the $t$ value gives some indication of the "significance" of that particular parameter. Although the model may be a good description of the data, the amount of "work" done by any particular parameter may be insignificant. Specifically, a parameter whose $t$ value is less than $t .025$ (with $n-p d f$ ) is considered not different ${ }^{2}$ from zero. Standard errors of the parameters give some indication of how well the parameters are determined. For example, if $\operatorname{SE} \theta_{\mathbf{j}}>\operatorname{SE} \theta_{\mathbf{i}}$, a parameter-parameter confidence region maps out an elliptical area where the major axis corresponding to $\theta_{\mathrm{j}}$ is larger than that corresponding to $\theta_{\mathbf{i}}$ (Draper $\&$ Smith, 1966). That is, for any particular value of $\theta_{i}$ there is a larger range of values of $\theta_{j}$ which holds the regression constant. This statistic indicates from the data peculiarities of the function and the importance of the kind or "quality" of work done by that parameter. 
Figure 1

\begin{tabular}{|c|c|}
\hline 0 & REM INPUT MODEL HERE (LINE 1) \\
\hline 1 & $\operatorname{DEF} F N A(T)=P(1) *(\operatorname{EXP}(-T / P(2))-\operatorname{EXP}(-T / P(3)))$ \\
\hline 2 & DIM $Z(50,50), Z 1(50,50)$ \\
\hline 4 & PRINT "NO. OF PARAMETERS, NO. OF DATA PTS.?" \\
\hline 5 & INPUT $N, M \backslash N 1=M$ \\
\hline 6 & PRINT“'SS RES.”; INPUT W \\
\hline 7 & PRINT “INPUT “N” PARAMETERS” \\
\hline 8 & FOR $\mathrm{J}=1$ TO $\mathrm{N}$ \\
\hline 9 & PRINT "P(“J")=";:INPUT P1(J) \\
\hline 10 & $P(J)=P 1(J) \backslash N E X T J$ \\
\hline 11 & REM CONSTANTS LINES $15-17$ \\
\hline 12 & REM LINE $15=$ CRITICAL $T$ VALUE \\
\hline 13 & REM LINE 16 =LABLE FOR LEVEL \\
\hline 14 & REM LINE 17 =SCALE VALUE FOR Y \\
\hline 15 & $Q=2.306$ \\
\hline 16 & $A=95$ \\
\hline 17 & $V=1$ \\
\hline 20 & FOR $\mathrm{J}=1$ TO $\mathrm{N}$ \\
\hline 25 & $\mathrm{~T}=-1 /(2 * \mathrm{M}) * \mathrm{~V}$ \\
\hline 30 & $K=1$ \\
\hline 31 & REM DO PARTIALS \\
\hline 35 & FOR I=1 TO M \\
\hline 40 & $\mathrm{~T}=\mathrm{T}+1 / \mathrm{M}^{*} \mathrm{~V}$ \\
\hline 45 & $\mathrm{P}=\mathrm{P}(\mathrm{J})$ \\
\hline 50 & $P(J)=.999 * P(J)$ \\
\hline 55 & GOSUB 1000 \\
\hline 60 & $P(J)=1.002 * P(J)$ \\
\hline 65 & GOSUB 1000 \\
\hline 70 & $\mathrm{Z}(\mathrm{I}, \mathrm{J})=(\mathrm{D}(2)-\mathrm{D}(1)) / 2.00000 \mathrm{E}-03 / \mathrm{P}$ \\
\hline 75 & $P(J)=.999 * P(J)$ \\
\hline 80 & NEXT I \\
\hline 85 & NEXT J \\
\hline 100 & REM TRANSPOSE Z \\
\hline 105 & FOR I= 1 TO N \\
\hline 110 & FOR J=1 TO M \\
\hline 115 & $\mathrm{Zl}(\mathrm{I}, \mathrm{J})=\mathrm{Z}(\mathrm{J}, \mathrm{I})$ \\
\hline 120 & NEXT J \\
\hline 125 & NEXT I \\
\hline 130 & REM ZT*Z \\
\hline 140 & FOR I=1 TO N \\
\hline 150 & FOR $J=1$ TO $N$ \\
\hline 155 & FOR $K=1$ TO M \\
\hline 160 & $A(I, J)=A(I, J)+(Z 1(I, K) * Z(K, J)$ \\
\hline 165 & NEXT $K$ \\
\hline 166 & NEXT J \\
\hline 168 & NEXT I \\
\hline 169 & REM COMPUTE INVERSE A \\
\hline 170 & $\mathrm{l}=1$ \\
\hline 171 & $M=N$ \\
\hline 175 & $\mathrm{~J}=\mathrm{M}+1$ \\
\hline 180 & $B=I+M$ \\
\hline 185 & IF $\mathrm{B}=\mathrm{J}$ THEN 198 \\
\hline 190 & $A(I, J)=0$ \\
\hline 195 & GO TO 200 \\
\hline 198 & $A(I, J)=1$ \\
\hline
\end{tabular}


Figure 1 Continued

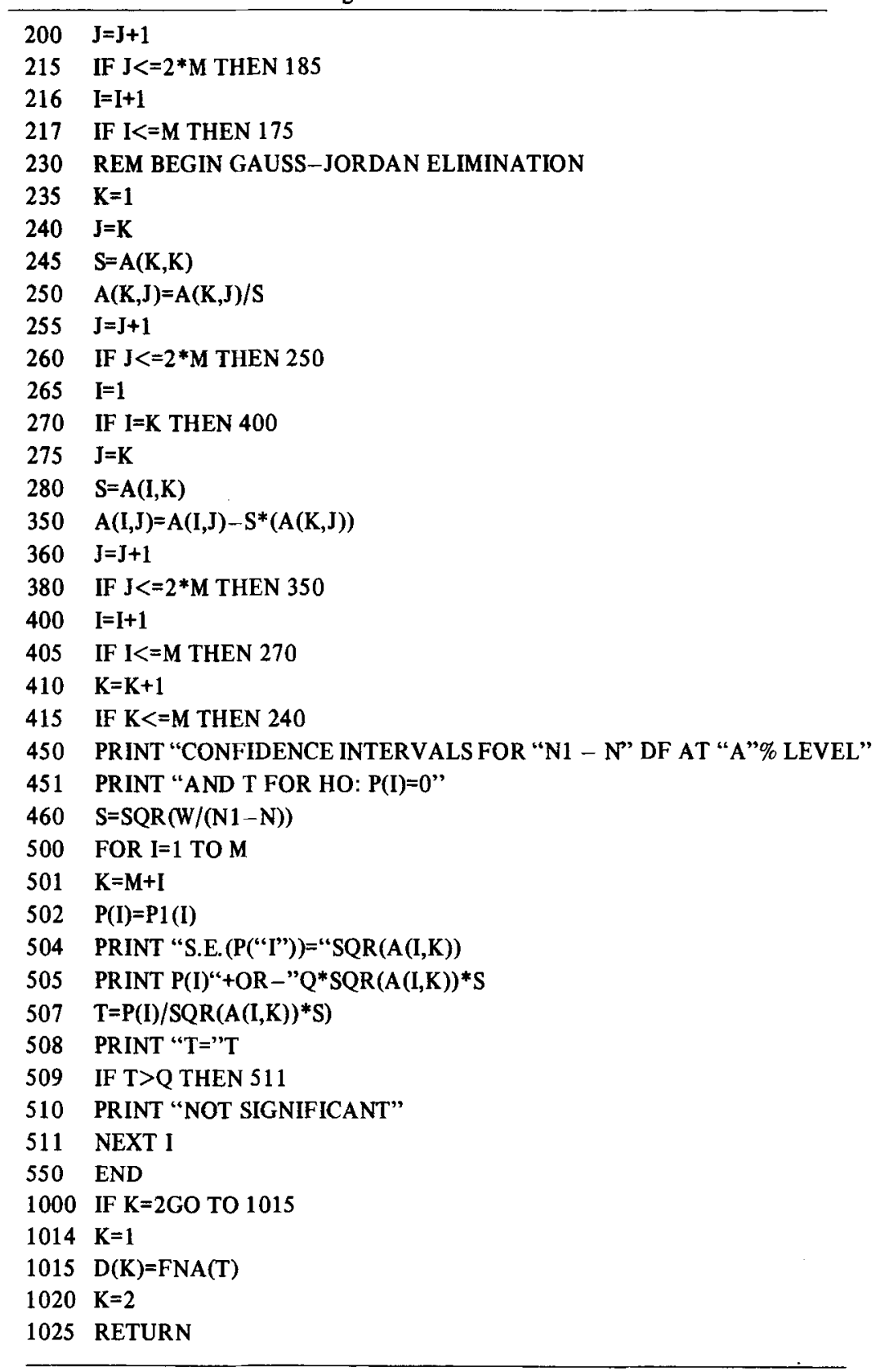

These statistical properties are output by CONF in a convenient format in the order in which the parameters were input (see Figure 2).

An Example. Killeen (1975) suggested a nonlinearizable function for the time course of general activity of pigeons between periodic brief feedings:

$$
R(t)=A\left(e^{-t / C}-e^{-t / I}\right), C>I, t>0 .
$$

This function is bitonic for $\mathrm{C}$ and $\mathrm{I}>0$, and rate of growth for decay from the maxima is governed by the two time constants $I$ and $C$. The time constants are indicants of two interacting exponential processes which arise between feedings. " $A$ " was taken as a measure of the motivation or arousal of the organism. These parameters were estimated on a PDP.11 minicomputer using a random leap-optimization algorithm (cf. Curry, 1975).

This model has been input as the user-defined function FNA at line 1 (see Figure 1), and two cases of the activity data are considered. The first case arises under one of the shortest interfood intervals and is quite peaked; that is, the data rise to and fall from its maxima quite rapidly. Nonetheless, this particular model de- 


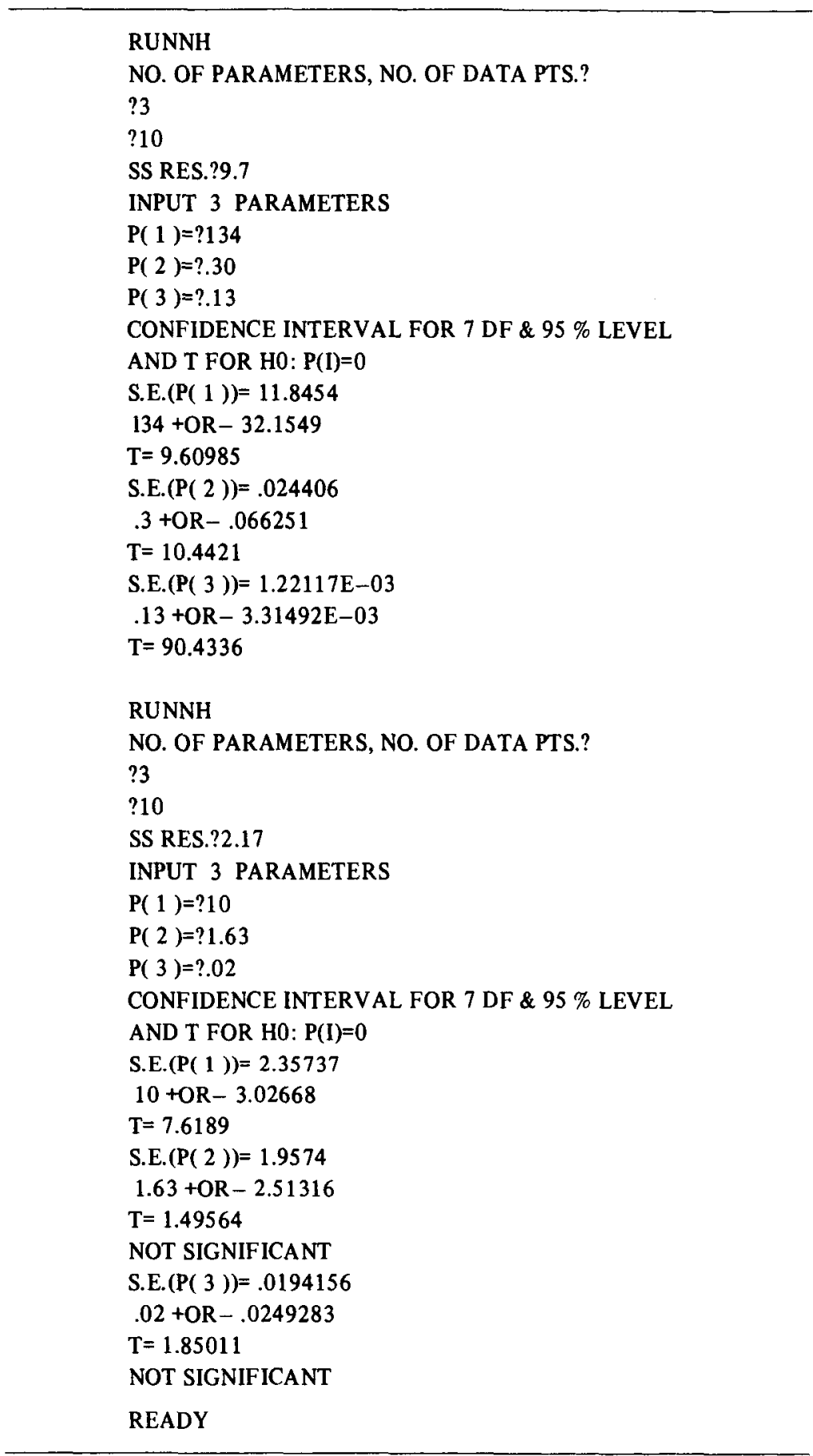

Figure 2

scribes the data quite well $\left(\omega^{2}=.99\right)$. The least squares estimates of Parameters A, C, and I were, respectively, $134, .30$, and .13 . This information was input into CONF and standard errors, $T$ values, and confidence intervals were computed for all three parameters. The sample run appears in the top of Figure 2.

Two aspects of the parameters are notable. First, as indicated by the $t$ values, all parameters are doing a "significant" amount of work. Second, due to the nature of the function, some parameters seem more constrained than others. For example, comparing the standard error of $I$ to either $C$ or $A$ indicates that the allowable range of the latter two parameters is much greater than that of I. Thus, changes in I have a much more significant effect on the fit than either of the other two parameters.

The second case is also interesting. The data were collected at one of the longest intervals, $200 \mathrm{sec}$. The 
data were nearly flat (see Killeen, 1975, Figure 1), although the best fit was that with a nonzero I value (increasing limb). The fit here too is quite good $\left(\omega^{2}=.97\right)$. The input parameters into CONF were $10(\mathrm{~A}), 1.63(\mathrm{C})$, and $.02(\mathrm{I})$. The sample run is shown at the bottom of Figure 2 .

The results of the run indicate that neither I nor $\mathrm{C}$ is necessary for the goodness of fit. Both $t$ values are less than that for a critical $.025 \mathrm{t}$ value $\mathrm{e}^{3}$ with $7 \mathrm{df}$. Also, the confidence intervals for these parameters are larger than the parameters themselves. " $A$ " on the other hand is quite constrained and appears to be the only hardworking parameter in this fit.

Across runs the parameter changes over some independent variable, and, in this case, interfood interval can be accompanied by corresponding confidence limit changes. Changes in confidence limits might be an important consideration when attempting to determine the kind of functional form the parameters take.

Computer. CONF was written and developed on a PDP-11/05 under the RT-11 operating system.

Availability. A listing of CONF with sample output is available at no cost upon request from the author at Arizona State University, Department of Psychology, Tempe, Arizona 85281.

\section{RÉFERENCES}

Blougr, D. S. Steady state data and a quantitative model of operant generalization and discrimination. Journal of Experimental Psychology: Animal Behavior Processes, 1975, 104, 3-22.

CURRY, R. E. A random search algorithm for laboratory computers. Behavior Research Methods \& Instrumentation, 1975, 7, 369-376.

DAvis, J. D., \& LEvine, M. W. A model for the control of ingestion. Psychological Review, 1977, 84, 379-412.

DRAPER, N. R., \& SMTTH, H. Applied regression analysis. New York: Wiley, 1966.

Gallant, A. R. Nonlinear regression. American Statistician, 1975, 29, 73-81.
Gibion, J. Scalar expectancy theory and Weber's Law in animal timing. Psychological Review, 1977, 84, 279-325.

Killeen, P. R. On the temporal control of behavior. Psychological Review, 1975, 82, 89-115.

Norman, D., \& Rumelhart, D. A system for perception and memory. In D. Norman (Ed.), Models of human memory. New York: Academic Press, 1970.

Rescorla, R., \& WAGNer, A. R. A theory of Pavlovian conditioning: Variations in the effectiveness of reinforcement and nonreinforcement. In A. H. Black \& W. F. Prokasy (Eds.), Classical conditioning II: Current research and theory. New York: Appleton-Century-Crofts, 1972.

Staddon, J. E. R. Behavioral competition in conditioning situations: Notes toward a theory of generalization and inhibition. In H. Davis \& H. M. B. Hurwitz (Eds.), OperantPavlovian interaction. New York: Wiley, 1977.

Staddon, J. E. R. Operant behavior as adaptation to constraint. Jourmal of Experimental Psychology: General, in press.

WiCKelGREN, W. Network strength theory of storage and retrieval dynamics. Psychological Review, 1976, 86, 466-478:

ZaJonc, R. B., \& Markos, G. B. Birth order and intellectual development. Psychological Review, 1975, 82, 74-88.

\section{NOTES}

1. The variable $T$ is normalized over $(0,1)$ for ready comparison of different data spans. However, note that if data are fit over a nonnormalized range, this variable must be altered in the program at line 17: Simply set $V$ equal to the upper limit of the range of the independent variable.

2. For time constants as in the present case (or any parameter which appears in a denominator), a test against either zero or infinity would be equivalent, since both values reduce the exponential terms to constants independent of $T$. However, one must be careful of the interpretation of the kind of "nonwork" the parameter is doing. Time constants close to zero indicate the process is almost over once it starts. On the other hand, time constants close to infinity indicate that the process is quite persistent.

3. The probability level may be altered at line 15 by setting $\mathrm{Q}$ equal to the appropriate critical $\mathrm{t}$ value (adjust $\mathrm{A}$ at line 16 also).

(Accepted for publication April 13, 1978.) 